\title{
Secular pattern of congenital oesophageal atresia
}

\author{
George Knox
}

(This article has been reproduced from the British fournal of Preventive and Social Medicine 1959;13:222-6.)

There is a common superstition among hospital staffs that rare diseases tend to come in groups. One possible explanation for this belief may be found in the character of the frequency distribution of lengths of intervals between successive events occurring at random. In contrast with the distributions of everyday experience, where, for example, a very short man is also an uncommon man, the distribution of random intervals is exponential, and the intervals become more frequent as they get shorter and further from the mean. The unfamiliarity of this pattern could easily produce impressions of grouping, and our chief difficulty is not in detecting groups of illnesses but in distinguishing random groups from those which could not reasonably be attributed to chance.

The present paper is an exercise in such distinction. Oesophageal atresia and tracheooesophageal fistula commonly occur in the same child and may be considered together as a relatively uncommon congenital malformation. Yet Gross (1953) was able to show on a single photograph no fewer than nine children who were patients at the Children's Hospital, Boston, for the treatment of this condition. At least six appear to be very young infants, presumably having a primary repair, and other statistics given suggest that this represents a remarkable coincidence of events. Indeed, it supplies a concise statement of the specific problem with which this paper is concerned.

MATERIAL

Two groups of children have been studied:

(1) All cases of tracheo-oesophageal fistula and/or oesophageal atresia admitted to the Birmingham Children's Hospital in the years 1950 to 1955 (Table I);

(2) All cases recorded at the Royal Victoria Infirmary, Newcastle General Hospital, Babies' Hospital, Fleming Memorial Hospital, and Princess Mary Maternity Hospital (all at Newcastle-upon-Tyne), at Dryburn Hospital, Durham, and at the Department of Thoracic Surgery, Shotley Bridge General Hospital, in the years 1950 to 1958 (Table II).

All the Birmingham children were liveborn, but two stillborn infants with the condition are included in the Newcastle group.

There were 35 cases at Birmingham in 6 years and 63 in the Newcastle hospitals in 9 years.
In neither series is it supposed that a defined population is represented or that ascertainment is complete. In recent years the recognition of the disease has been improving, so that in any series we can presume that earlier records are less complete than later ones, and since current standards of diagnosis are not uniform we must suppose that even recent records are incomplete.

The dates of birth of the Birmingham and Newcastle babies given in Tables I and II are grouped by year and month in Tables III and IV.

\section{ANALYSIS}

It is immediately obvious that neither series is random. In both groups there is wide variation between the numbers occurring in different years:

$$
\begin{aligned}
& \text { Birmingham } \chi^{2}(5)=23.9 ; p<0.001 ; \\
& \text { Newcastle } \chi^{2}(8)=31.4 ; p<0.001
\end{aligned}
$$

Table I 35 Cases of oesophageal atresia/tracheo-

\begin{tabular}{|c|c|c|}
\hline Date of birth & Day number & $\begin{array}{l}\text { Preceding interval } \\
\text { (days) }\end{array}$ \\
\hline $\begin{array}{l}19.6 .50 \\
12.11 .50 \\
21.3 .51 \\
13.4 .51 \\
26.7 .52 \\
30.10 .52 \\
1.2 .53 \\
17.5 .53 \\
1.6 .53 \\
2.6 .53 \\
5.6 .53 \\
12.6 .53 \\
20.6 .53 \\
28.7 .53 \\
16.10 .53 \\
19.10 .53 \\
21.10 .53 \\
16.12 .53 \\
24.12 .53 \\
28.12 .53 \\
31.12 .53 \\
30.1 .54 \\
2.5 .54 \\
26.8 .54 \\
29.8 .54 \\
22.11 .54 \\
8.4 .55 \\
28.5 .55 \\
11.8 .55 \\
13.8 .55 \\
29.8 .55 \\
6.9 .55 \\
9.10 .55 \\
21.11 .55 \\
14.12 .55 \\
\text { End of Period } \\
\text { Total Number of } \\
\text { Days } \\
\end{array}$ & $\begin{array}{l}170 \\
316 \\
445 \\
468 \\
938 \\
1034 \\
1128 \\
1233 \\
1248 \\
1249 \\
1252 \\
1259 \\
1267 \\
1305 \\
1385 \\
1388 \\
1390 \\
1446 \\
1454 \\
1458 \\
1461 \\
1491 \\
1583 \\
1699 \\
1702 \\
1787 \\
1924 \\
1974 \\
2049 \\
2051 \\
2067 \\
2075 \\
2108 \\
2151 \\
2174 \\
2191\end{array}$ & $\begin{array}{r}170 \\
146 \\
129 \\
23 \\
470 \\
96 \\
94 \\
105 \\
15 \\
1 \\
3 \\
7 \\
8 \\
38 \\
80 \\
3 \\
2 \\
56 \\
8 \\
4 \\
3 \\
30 \\
92 \\
116 \\
3 \\
85 \\
137 \\
50 \\
75 \\
2 \\
16 \\
8 \\
33 \\
43 \\
23 \\
17\end{array}$ \\
\hline
\end{tabular}
oesophageal fistula in Birmingham
Medicine, University of Birmingham, and the Department of Child Health, University of Durham, at King's College, Newcastle upon Tyne. 
Table II 63 Cases of oesophageal atresia/tracheooesophageal fistula in the Newcastle region

\begin{tabular}{|c|c|c|}
\hline Date of birth & Day number & $\begin{array}{l}\text { Preceding interval } \\
\text { (days) }\end{array}$ \\
\hline $\begin{array}{l}15.2 .50 \\
7.1 .51 \\
12.1 .51 \\
26.2 .51 \\
19.5 .51 \\
12.6 .51 \\
20.8 .51 \\
6.11 .51 \\
29.11 .51 \\
22.11 .52 \\
16.2 .53 \\
15.7 .53 \\
24.7 .53 \\
9.8 .53 \\
14.9 .54 \\
20.9 .54 \\
29.11 .54 \\
8.1 .55 \\
17.1 .55 \\
30.1 .55 \\
5.2 .55 \\
8.2 .55 \\
21.2 .55 \\
24.3 .55 \\
25.3 .55 \\
27.3 .55 \\
26.4 .55 \\
16.5 .55 \\
19.7 .55 \\
22.7 .55 \\
11.9 .55 \\
29.10 .55 \\
14.11 .55 \\
6.1 .56 \\
28.1 .56 \\
9.3 .56 \\
13.5 .56 \\
17.5 .56 \\
20.5 .56 \\
24.5 .56 \\
11.7 .56 \\
26.9 .56 \\
22.11 .56 \\
2.12 .56 \\
15.2 .57 \\
10.3 .57 \\
14.5 .57 \\
15.5 .57 \\
20.8 .57 \\
19.9 .57 \\
2.10 .57 \\
1.1 .58 \\
28.5 .58 \\
29.5 .58 \\
11.6 .58 \\
23.6 .58 \\
28.6 .58 \\
14.8 .58 \\
12.9 .58 \\
17.9 .58 \\
16.10 .58 \\
28.11 .58 \\
21.12 .58 \\
\text { End of Period } \\
\text { Total Number of } \\
\text { Days } \\
\end{array}$ & 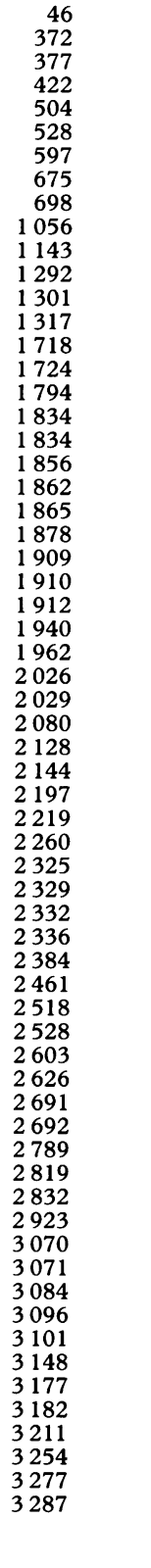 & 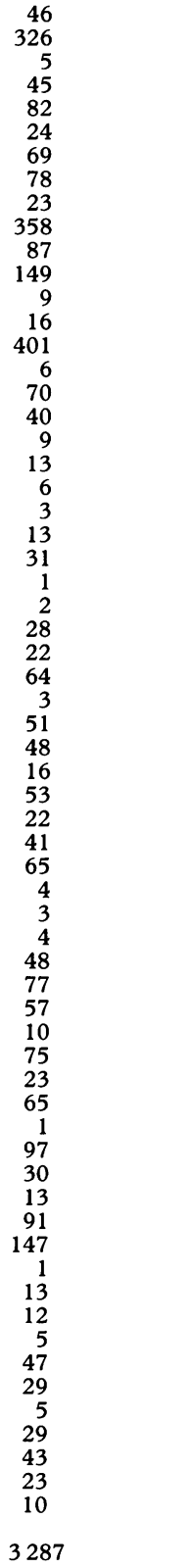 \\
\hline
\end{tabular}

Both sets of annual totals show a general rise in recorded incidence with time and a possible reason for this, or at least a contributing reason, has already been suggested.

In neither group, however, does a linear trend supply an adequate description of the series of annual totals, both series showing highly significant deviations about the calculated regressions.

The combined data. of both series show no evidence of a seasonal cycle.

Superimposed upon the pattern of an irregular increase can be seen (see Tables III and IV) the groups constituting the problem which is the subject of this paper:

In Birmingham, there occurred three close groups in the Summer, Autumn, and Winter of 1953, a close pair of cases in 1954, and another less striking concentration in the late Summer of 1955.

In Newcastle the more striking groups were in January, 1951, the Summer of 1953, and the Spring or Summer of each year from 1955 to 1958 .

These irregularly recurring groups, combined with the evident irregularity and nonlinearity of the annual totals, suggest a nonrandom element over and above anything which could be attributed to improving ascertainment.

Unfortunately, no established significance test appears to be directly applicable, and the formal examination of the situation depends upon ad hoc methods with the accompanying logical difficulties which arise when there is a wide choice of tests and no prior reasons for using any particular one preferentially.

The simplest method of constructing a numerical picture of the extent of the concentrations is to draw up the distribution of numbers of cases occurring within successive arbitrary equal periods of time after index cases. Each case is used in turn as the index. Because all "secondary" cases in the appropriate periods are counted, not just the first subsequent ones, the distribution expected in a random distribution is rectangular and not exponential. Thus we expect the sum of cases occurring in the period 0 to 6 days after the index cases to be the same as those occurring in each of the periods 7 to 13 days, 14 to 20 days, and so on. Furthermore, we can easily calculate the expected number for each period from the total number of cases seen and the total period covered. Results of such counts and calculations are given in Table V. They seem to show that within 2 and possibly 4 weeks of a case there was an increased risk of another, but that this was not evident after 4 weeks. This degree of concentration suggests an oscillation of shorter period than that due to the trend in the completeness of ascertainment, and there were no systematic seasonal variations which could have supplied an oscillation of this type.

Table III Oesophageal atresia and tracheo-oesophageal fistula in Birmingham, by date of birth, 1950-55

\begin{tabular}{|c|c|c|c|c|c|c|c|c|c|c|c|c|c|c|}
\hline Month & & 1 & 2 & 3 & 4 & 5 & 6 & 7 & 8 & 9 & 10 & 11 & 12 & $\begin{array}{l}\text { Total } \\
\text { cases } \\
\text { per year }\end{array}$ \\
\hline Total cases & $\begin{array}{l}1950 \\
1951 \\
1952 \\
1953 \\
1954 \\
1955 \\
\text { per month }\end{array}$ & $\begin{array}{l}\bullet \\
1\end{array}$ & • & 1 & $\stackrel{\bullet}{2}$ & $\begin{array}{l}\bullet \\
\bullet \\
\end{array}$ & 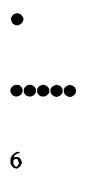 & $\begin{array}{l}\bullet \\
\bullet \\
2\end{array}$ & $\begin{array}{l}\bullet \bullet \\
\bullet \bullet \bullet \\
5\end{array}$ & : & $\begin{array}{l}\bullet \\
\bullet \bullet \\
5\end{array}$ & • & $\begin{array}{l}2 \\
\bullet \bullet \bullet \\
\bullet\end{array}$ & $\begin{array}{r}2 \\
2 \\
15 \\
5 \\
9 \\
35\end{array}$ \\
\hline
\end{tabular}


Table IV Oesophageal atresia and tracheo-oesophageal fistula in the Newcastle region, by date of birth, 1950-58

\begin{tabular}{|c|c|c|c|c|c|c|c|c|c|c|c|c|c|c|}
\hline \multicolumn{2}{|l|}{ Month } & 1 & 2 & 3 & 4 & 5 & 6 & 7 & 8 & 9 & 10 & 11 & 12 & $\begin{array}{l}\text { Total cases } \\
\text { per year }\end{array}$ \\
\hline Total & $\begin{array}{l}1950 \\
1951 \\
1952 \\
1953 \\
1954 \\
1955 \\
1956 \\
1957 \\
1958 \\
\text { per month }\end{array}$ & $\bullet$ & $\begin{array}{l}\bullet \\
\bullet \\
\bullet \\
\bullet \bullet \\
\bullet \\
7\end{array}$ & $\begin{array}{l}\bullet \bullet \\
\bullet \\
5\end{array}$ & - & $\begin{array}{l}\bullet \\
\bullet \bullet \\
\bullet \bullet \\
10\end{array}$ & $\bullet$ & $\bullet$ & 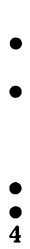 & $\begin{array}{l}\bullet \bullet \\
\bullet \\
\bullet \\
\bullet \\
\bullet \\
0\end{array}$ & $\begin{array}{l}\bullet \\
\bullet \\
3\end{array}$ & $\begin{array}{l}\bullet \\
\bullet \\
\bullet \\
\bullet \\
\bullet \\
\bullet\end{array}$ & $\begin{array}{l}\bullet \\
\bullet \\
2\end{array}$ & $\begin{array}{r}1 \\
8 \\
1 \\
\\
3 \\
16 \\
11 \\
7 \\
12 \\
63\end{array}$ \\
\hline
\end{tabular}

While this technique of presentation supplies an adequate descriptive statistic in these circumstances, it presents unfortunate difficulties in relation to possible tests of significance. Regarded as Poisson terms, the totals for each of the first subsequent 3 weeks in the Birmingham series, and both the first week and first fortnight in the Newcastle series, could be regarded as significantly high. But it is not obvious that the events can be regarded as independent when the counts are made in this way and some, clearly, are counted more than once. The same difficulties apply to the $\chi^{2}$ test.

Returning to the exponentially distributed lengths of intervals between successive cases, we can calculate, from the mean interval and by reference to a table of exponential functions, the number of intervals of less than 2 weeks which we should expect to observe at both Birmingham and Newcastle under conditions of randomly occurring events. The mean interval ( $\bar{t}$ ) at Newcastle was 52.17 days, and at Birmingham 62.60 days (the series being supposed as annular for the purpose), so that 2 weeks represents $0.268 \overline{\mathrm{t}}$ at Newcastle and $0.224 \overline{\mathrm{t}}$ at Birmingham. From this, we expect 0.237 of the intervals at Newcastle (i.e. 14.9) and 0.206 of intervals at Birmingham (i.e. 7.2) to be in the range 0-13 days. The observed figures (see Tables I and II) were 22 at Newcastle and 12 at Birmingham: a total of 34 against an expected 22.1. This is a significant excess.

However, although it is legitimate here to regard the figures as Poissonian variables, this approach is somewhat arbitrary and depends upon selection of an interval after inspecting the data, and in any case does not distinguish

Table $V$ Number of cases of oesophageal atresia/tracheo-oesophageal fistula occurring in successive weeks after index cases

\begin{tabular}{cllccccc}
\hline Number of days after index case & $0-6$ & $7-13$ & $14-20$ & $21-27$ & $28-41$ \\
\hline Length of Interval (days) & & 7 & 7 & 7 & 7 & 14 \\
No of cases & Observed & 15 & 12 & 6 & 12 & 18 \\
& Birmingham & Expected* & 8.3 & 8.3 & 8.3 & 16.6 & 7 \\
& Observed & 10 & 8 & 9 & 5 & 7 \\
Total & Expected* & 3.8 & 3.8 & 3.8 & 3.8 & 7.6 \\
& Observed & 25 & 20 & 15 & 17 & 25 \\
& Expected & 12.1 & 12.1 & 12.1 & 12.1 & 24.2 \\
& Excess as & 107 & 65 & 24 & 40 & 3 \\
& percentage of & & & & & \\
\hline
\end{tabular}

\footnotetext{
* "Expected" values calculated by supposing the time series to be circular.

Thus the expected value for 7 days, following one case, in Newcastle is $\frac{62 \times 7}{3,287}$ and, following 63 index cases, it is $\frac{62 \times 63 \times 7}{3,287}$

For Birmingham the expected value is $\frac{34 \times 35 \times 7}{2,191}$

The actual values were also calculated by presuming that the series was circular
}

clearly between clustering and trend. The same objections apply to most other ad hoc techniques.

\section{DISCUSSION}

The first regrettable conclusion is that direct attempts to approach the question of clustering are fraught with difficulties which permit only indirect inferences.

Thus, it can be shown satisfactorily that the distributions are not random in time, and that there are significant irregularities about linear trends, while the nature of the distributions does not suggest that more complex trends in improvement in diagnosis or ascertainment could supply a full explanation. Secondly, appropriate means of analysis provide a picture which strongly suggests the occurrence of shortterm clustering on repeated irregularly-spaced occasions and the absence of a systematic seasonal variation. These methods are not obviously susceptible to direct tests of significance.

It is surprising that there are no established general criteria of epidemicity, yet this seems indeed to be the case. However, if we make the presumption that there are probably no sources of variation here, other than more or less linear trends in the completeness of ascertainment or in the population at risk, and a possible tendency towards epidemicity, we could permissibly infer from the results that tracheo-oesophageal fistula (and/or congenital atresia of the oesophagus) is an epidemic disease. This is admittedly an oblique approach, but available methods seem to offer no alternatives and, in so far as the presumptions are reasonable, the conclusion likewise is reasonable.

The possible mechanism is a separate question and one which has not yet been investigated. The only matter of concern here is the question of artefact, in particular whether the occurrence of one case could so improve diagnosis in the ensuing weeks as to cause a temporary improvement in the likelihood of diagnosis of the next case. On a priori grounds it would seem unlikely that such an improvement could be so temporary, but there was also some evidence from the addresses of these children. There were in fact no close groups in time which were also close in space or which were born in the same hospital; in short, there was no evidence from direct examination that the individual doctors or midwives responsible for the initial diagnosis or investigation ever had 
closely repeated situations of this kind thrust upon them.

It seems far more likely that the clustering is a true biological phenomenon and analogy with the maternal rubella phenomenon would suggest infective origins.

\section{SUMMARY}

The question of clustering of events in time is discussed in relation to the occurrence at Birmingham and at Newcastle of tracheo-oesophageal fistula and/or oesophageal atresia.

Attempts are made to apply direct critical tests for epidemicity, but an oblique approach is finally used to reach the conclusion that true clustering occurs.

It is suggested that the disease may have an infective origin similar to that of the congenital malformations which have been seen to follow maternal rubella.

Besides many colleagues in the two departments in which this work was done, I wish to thank especially Professor J. M Smellie, Mr. G. A. Mason, Dr. J. M. Stansfeld, and Dr. G. A Anderson for help in tracing material. The first part of this work was carried out during the tenure of a Medical Research Council Clinical Research Fellowship.

Gross, RE. (1953). "The Surgery of infancy and Childhood". Saunders, Philadelphia and London. 